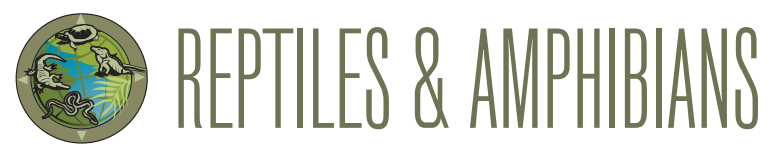

\title{
Predation by a Cuban Brown Curlytail (Leiocephalus cubensis) on a Cuban Green Anole (Anolis porcatus)
}

Luis F. de Armas

P.O. Box 4327, San Antonio de los Baños, Artemisa 38100, Cuba (luisdearmas1945@gmail.com)

$\mathrm{T}$ he Cuban Brown Curlytail, Leiocephalus cubensis (Gray 1840), which is widely distributed across the Cuban Archipelago, comprises five subspecies (Rodríguez Schettino 1999; Henderson and Powell 2009). The distribution of the nominal subspecies ranges from Artemisa to Sagua de Tánamo (Rodríguez Schettino 1999). Its diet consists largely of insects, of which ants are most abundant, especially in young lizards (Martinez Reyes and Fernandez Garcia 1999; Henderson and Powell 2009; pers. obs.). Nevertheless, three incidents of cannibalism and one of predation on a neonatal
Cuban Brown Anole, Anolis sagrei Duméril and Bibron 1837, were observed in an urban population in La Habana Province (Martínez Reyes and Fernández García 1994).

At 1344 h on 10 November 2021, a subadult L.c. cubensis (SVL $53 \mathrm{~mm}$ ) seized a juvenile Cuban Green Anole, Anolis portacus Gray 1840 (SVL $-30 \mathrm{~mm}$ ), on the ground in an urban yard in San Antonio de los Baños, Artemisa Province, Cuba (22 $53^{\prime} 36.49^{\prime \prime} \mathrm{N}, 82^{\circ} 30^{\prime} 35.21^{\prime \prime W}$; elev. $75 \mathrm{~m}$ asl.). The curlytail grasped the anole's body (Fig. 1A), killed it quickly, reoriented its body (Fig. 1B), and ingested it (Fig. 1C-D).
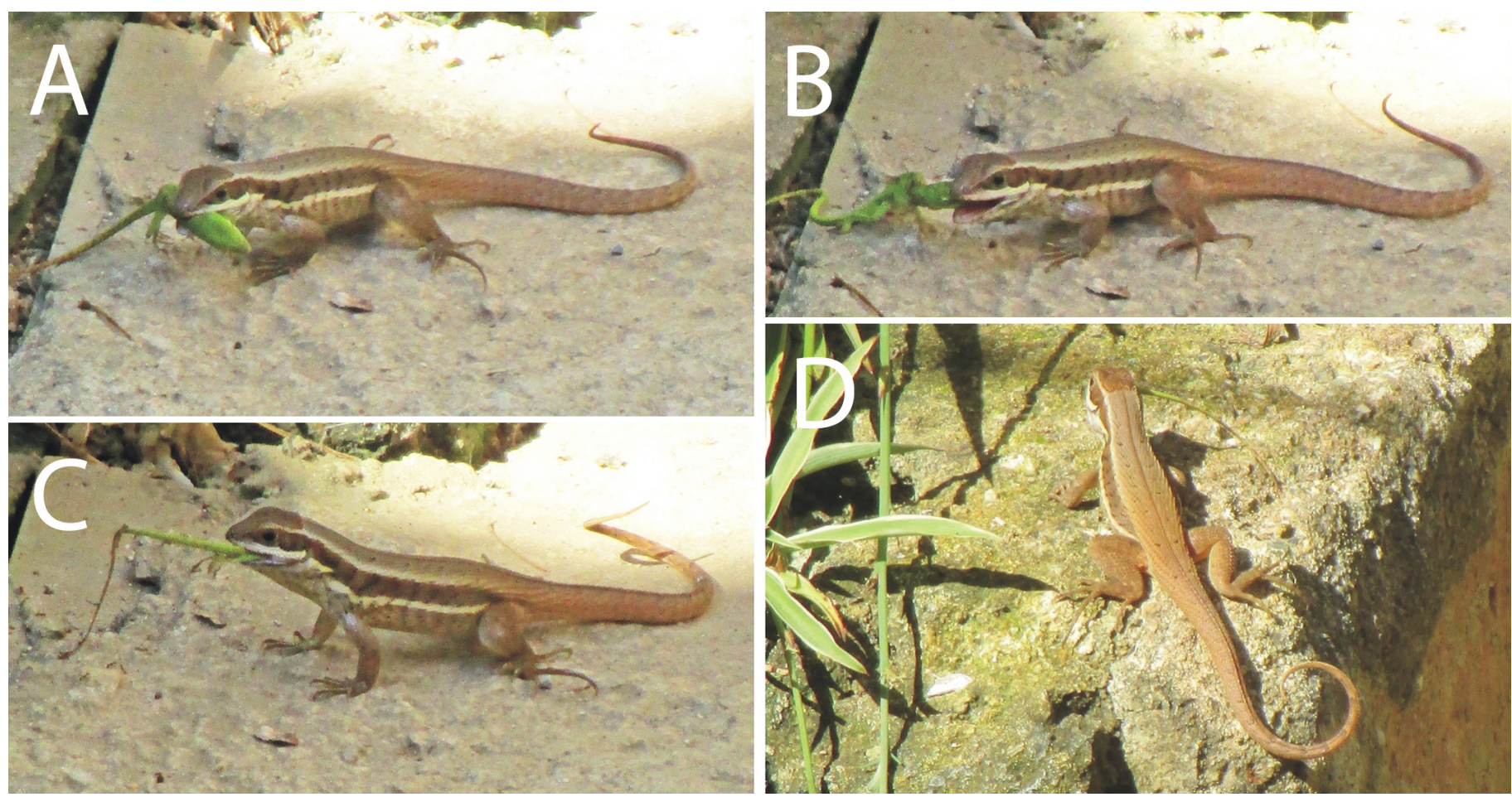

Fig. 1. A subadult Cuban Brown Curlytail (Leiocephalus c. cubensis) preying on a juvenile Cuban Green Anole (Anolis porcatus) in an urban yard in San Antonio de los Baños, Artemisa, Cuba. Photographs A-D were taking at two, three, four, and five minutes, respectively, after the anole was seized. Photographs by the author. 
The entire process took $6 \mathrm{~min}$. This is the first record of $L$. cubensis preying on $A$. porcatus and the second record of this curlytail feeding on an anole.

Other identifiable prey contained in fecal pellets of this curlytail in November and December 2021 were Jamaican Field Crickets, Gryllus assimilis (Orthoptera: Gryllidae); Surinam Cockroaches, Pycnoscellus surinamensis (Blattaria: Blaberidae); larval and adult Leaf Beetles, Leucocera poeyi (Coleoptera: Chrysomelidae); Western Honey Bees, Apis mellifera (Hymenoptera: Apidae); and many African Big-headed Ants, Pheidole megacephala (Hymenoptera: Formicidae). I also observed it eating small amounts of ripe fruit, including Papaya (Carica papaya) and Asparagus Fern (Asparagus densiflorus).

\section{Literature Cited}

Henderson, R.W. and R. Powell. 2009. Natural History of West Indian Reptiles and Amphibians. University Press of Florida, Gainesville, Florida, USA.

Martínez Reyes, M. and I. Fernández García. 1994. Hábitat y alimentación de Leiocephalus cubensis cubensis (Iguania: Tropiduridae) en una localidad de Ciudad de La Habana, Cuba. Ciencias Biológicas, 26: 21-30.

Rodríguez Schettino, L. 1999. Systematic accounts of the species, pp. 104-380. In: L. Rodríguez Schettino (ed.), The Iguanid Lizards of Cuba. University Press of Florida, Gainesville, Florida, USA. 